NOTE

\title{
Radiocarbon content and stable carbon isotopic ratios of individual fatty acids in subsurface soil: Implication for selective microbial degradation and modification of soil organic matter
}

\author{
Kohei Matsumoto, ${ }^{1 *}$ Kimitaka KaWAmura, ${ }^{1}$ Masao Uchida ${ }^{2}$ and YasuYUKi Shibata ${ }^{3}$ \\ ${ }^{1}$ Institute of Low Temperature Science, Hokkaido University, N19 W8, Kita-ku, Sapporo 060-0819, Japan \\ ${ }^{2}$ Japan Marine Science and Technology Center, 2-15 Natsushima-cho, Yokosuka 237-0061, Japan \\ ${ }^{3}$ National Institute for Environmental Studies, 16-2 Onogawa, Tsukuba 305-0053, Japan
}

(Received July 27, 2006; Accepted July 27, 2007)

\begin{abstract}
A subsurface soil sample was studied for molecular composition and stable carbon isotopic ratios $\left(\delta^{13} \mathrm{C}\right)$ of fatty acids (FAs) using a capillary gas chromatography (GC) and GC/combustion/isotope ratio mass spectrometer, respectively. Compound specific radiocarbon analyses of FAs were also conducted using an off-line preparative capillary GC/accelerator mass spectrometer. Molecular distribution of FAs $\left(\mathrm{C}_{14}-\mathrm{C}_{32}\right)$ is characterized by even carbon numbered predominance with two maxima at $n-\mathrm{C}_{16}$ and $n-\mathrm{C}_{28}$, being similar to that of plant leaf. However, branched chain $\mathrm{C}_{15}$ and $\mathrm{C}_{17}$ acids were abundant in soil, indicating bacterial degradation and modification of soil organic carbon. The $\delta^{13} \mathrm{C}$ of FAs ( -35.2 to $-23.0 \%$ ) are within the range of plant leaf $\delta^{13} \mathrm{C}\left(-36.4\right.$ to $-31.2 \%$ ) , except for heavy values $(-23.0$ to $-28.1 \%)$ of $\mathrm{C}_{14}$ to $\mathrm{C}_{18}$. The heavier $\delta^{13} \mathrm{C}$ values are most likely interpreted by microbial re-synthesis of shorter chain FAs in soil. We also report, for the first time, a significant diversity of $\Delta{ }^{14} \mathrm{C}$ values $(+17$ to $+127 \%)$ in soil FAs, with higher values (+96 to $+127 \%$ ) for saturated and unsaturated $\mathrm{C}_{18}$ and lower values $\left(+16\right.$ to $+19 \%$ ) for longer chain $\mathrm{C}_{28}$ and $\mathrm{C}_{30}$. The higher radiocarbon values can be explained by a combination of selective microbial decomposition of shorter chain FAs in subsurface soil, and the subsequent deposition and mixing of modern carbon with old carbon in soil. The modern carbon may be transported downward in the form of shorter chain FAs and other water-soluble organic compounds by meteoric water and/or tree roots, followed by microbial re-synthesis of lipids in soil. This study implies that microbial degradation and modification of soil organic matter play an important role in geochemical processes which control the carbon cycle on the Earth.
\end{abstract}

Keywords: compound specific radiocarbon and isotope analysis (CSRA and CSIA), soil organic carbon, monocarboxylic (fatty) acid, turnover rate and residence time, soil carbon cycles

\section{INTRODUCTION}

Soil organic carbon is one of the largest reservoirs in the global carbon cycle (IPCC, 2001). Although carbon uptake by soil has been thought to be balanced by respiration, mineralization and erosion, some forest sites including southern China and boreal soil are considered to accumulate refractory organic carbon that is fixed from atmospheric $\mathrm{CO}_{2}$ (Zhou et al., 2006; Smittenberg et al., 2006). Hence, the biogeochemical processes of the organic matter in a soil system needs to be better understood in relation to the global carbon cycle. The carbon

*Corresponding author (e-mail: kohei@jamstec.go.jp)

* Present address: Graduate School of Tokyo Metropolitan University,

1-1 Minami-Osawa, Hachioji 192-0397, Japan.

Copyright $@ 2007$ by The Geochemical Society of Japan. cycle in a soil system, including microbial mineralization of organic matter to $\mathrm{CO}_{2}$, is closely linked to that of the atmosphere, whose reservoir size is rather small but sensitive to global changes. Many studies have been conducted in soil organic matter to investigate the turnover rates and soil respiration at elemental carbon levels. More recently, radiocarbon measurement of bulk soil organic matter has been conducted, including incubation experiments of soils and decomposition experiments of spiked lipids (e.g., Genty et al., 1998; Richter et al., 1999; Gaudinski et al., 2000; Becker-Heidmann et al., 2002; Neff et al., 2002).

In a forest, litters are decomposed by animals and modified by microorganisms to result in soil organic matter. They are further subjected to various biogeochemical processes. A combined molecular, stable carbon and radiocarbon analysis could provide a powerful tool to understand the sources, transport mechanisms and micro- 
bial process of soil organic matter. For example, longer chain fatty acids (FAs) $>\mathrm{C}_{20}$ are characteristic of leaf waxes whereas shorter chain $\mathrm{FAs}<\mathrm{C}_{20}$ are important components of leaf cell membrane as well as microorganisms. Using ${ }^{14} \mathrm{C}$ content in fatty acids, we could better discuss the biogeochemical cycle and fates of the terrestrial organic matter in the soil system. Although stable carbon isotopic composition (e.g., Hayes et al., 1990; Huang et al., 1996; Naraoka et al., 1999; Lichtfouse, 2000) and radiocarbon analyses (Pearson et al., 2001; Uchida et al., 2000, 2001; Smittenberg et al., 2006) of lipid class compounds have been reported in sediments, radiocarbon analysis of individual organic molecules has rarely been conducted in soil samples. Lichtfouse et al. (1997a, b) determined molecular distribution, ${ }^{13} \mathrm{C}$ and ${ }^{14} \mathrm{C}$ of hydrocarbon fractions from modern soil samples, and provided some evidence on their fossil fuel origin. More recently Kramer and Gleixner (2006) reported, based on ${ }^{13} \mathrm{C}$ and ${ }^{14} \mathrm{C}$ analyses of FAs in soils, a preferential uptake of plantderived fresh carbon by gram-positive bacteria.

A significant amount of Chinese loess (Kosa) is occasionally transported over the Japanese Islands and the western North Pacific in spring (Huebert et al., 2003; Kawamura et al., 2004). Asian soil dusts are in part transported over North America (Perry et al., 1999). In the open ocean, continental organic carbon is believed as a significant source of the organic matter in the deep-sea sediments (Gagosian and Peltzer, 1986; Kawamura, 1995). Thus, atmospheric deposition of continental soils and associated organic matter may have an impact on the soil system as well. Matsumoto et al. (2001) analyzed ${ }^{14} \mathrm{C}$ in individual FAs isolated from semi-urban aerosols in Sapporo, Japan and reported a relatively old age (up to $\sim 5800$ years BP) of long chain fatty acids that are derived from terrestrial higher plants. This study suggested that some fractions of long chain FAs in the aerosols have been stored in geochemical reservoirs such as soils for geological time and then transported to the atmosphere by wind.

In order to understand the sources and biogeochemical cycle of soil carbon, we conducted organic geochemical and stable/radiocarbon isotopic studies of fatty acids. Here, we report, for the first time, the abundances, stable carbon isotopic compositions and radiocarbon contents of individual FAs in a subsurface soil sample using Gas Chromatography (GC), GC/Isotope Ratio Mass Spectrometry (GC/IRMS) and off-line Preparative Capillary GC (PCGC)/Accelerator Mass Spectrometry (AMS). The PCGC/AMS method has been developed as Compound Specific Radiocarbon Analysis (CSRA) (Eglinton et al., 1996) and applied to various marine sediments (e.g., Pearson et al., 2001). Using stable carbon isotopic composition of individual organic compound in a soil sample together with their ${ }^{14} \mathrm{C}$ data, we discuss

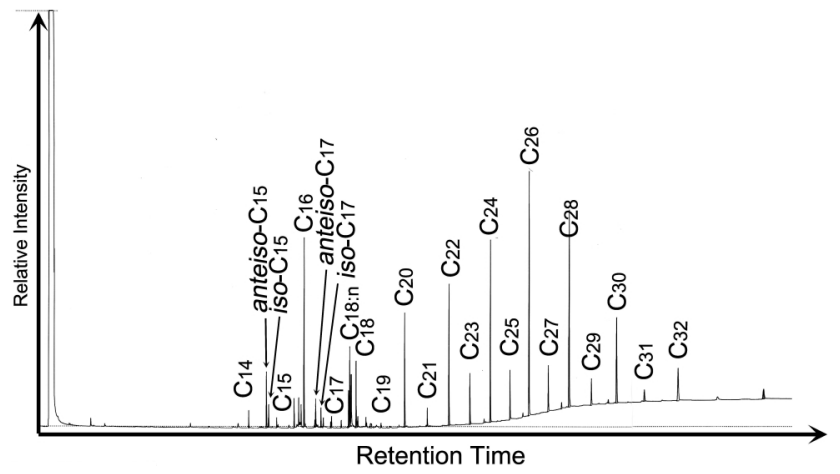

Fig. 1. A typical gas chromatogram (GC/FID) of monocarboxylic acid methyl ester fraction isolated from the soil sample.

the sources and biogeochemical processes of FAs in a soil system.

\section{SAMPLE AND METHOD}

A subsurface soil sample $(20-30 \mathrm{~cm}$ in depth) was collected in 2000 in a forest area on the campus of the Institute of Low Temperature Science (ILTS), Hokkaido University, Sapporo, Japan. This depth layer was chosen to avoid a direct influence from anthropogenic sources including atmospheric deposition of fossil fuel combustion products. Inceptisols (United States Department of Agriculture, 2003) and cambisols (Food and Agriculture Organization of the United Nations, 1998) are major soil types around the sampling site. The sampling site has not been used for agricultural purposes since Hokkaido University was established 130 years ago. In addition, there is no evidence of historical forest fire around the sampling site and graphitic materials such as black carbons were not observed in the sample. The color of the soil sample is dull yellow orange (10YR 6/3). Pebbles, roots and leaves were removed using tweezers from the sample to avoid obstructions during lipid analyses. The sample was dried in an oven $\left(60^{\circ} \mathrm{C}, 3\right.$ days $)$ prior to analysis.

The dried soil sample $(50 \mathrm{~g})$ was extracted with a methanol and methylene chloride mixture to separate the lipid fraction (Matsumoto et al., 2001). The extracts were saponified and the neutral fraction was removed by solvent extraction. The remaining saponified solution was acidified with $\mathrm{HCl}$, from which $\mathrm{FAs}$ were extracted with $\mathrm{CH}_{2} \mathrm{Cl}_{2}$. Fatty acids were then derivatized to methyl esters using $14 \% \mathrm{BF}_{3}$ in methanol, and the ester faction was further purified to isolate monocarboxylic acid methyl esters on a silica gel chromatography column (see Kawamura, 1995). In order to obtain concentrations of FAs and their stable carbon isotopic composition, an aliquot of the ester fraction was analyzed using a capil- 
Table 1. The abundance, carbon isotopic compositions and CPI value of fatty acids in the soil sample

\begin{tabular}{|c|c|c|c|}
\hline Carbon number & Abundance $(\mu \mathrm{g} / \mathrm{g}$ dry soil) & $\delta^{13} \mathrm{C}(\%)$ & Standard deviation \\
\hline $\mathrm{C}_{14}$ & 0.67 & -27.3 & 0.4 \\
\hline anteiso- $\mathrm{C}_{15}$ & 2.07 & -24.3 & 0.7 \\
\hline iso- $\mathrm{C}_{15}$ & 0.90 & -24.6 & 0.5 \\
\hline $\mathrm{C}_{15}$ & 0.39 & -23.0 & 0.9 \\
\hline $\mathrm{C}_{16}$ & 6.72 & -28.1 & 0.2 \\
\hline anteiso- $\mathrm{C}_{17}$ & 0.71 & -24.4 & 1.8 \\
\hline iso- $\mathrm{C}_{17}$ & 0.40 & -23.7 & 1.5 \\
\hline $\mathrm{C}_{17}$ & 0.24 & -25.8 & 2.6 \\
\hline $\mathrm{C}_{18: n} *$ & 6.49 & -26.5 & 0.9 \\
\hline $\mathrm{C}_{18: 0}$ & 2.41 & -25.3 & 1.0 \\
\hline $\mathrm{C}_{19}$ & 0.21 & -30.2 & 0.6 \\
\hline $\mathrm{C}_{20}$ & 4.11 & -30.4 & 0.9 \\
\hline $\mathrm{C}_{21}$ & 0.70 & -30.5 & 0.8 \\
\hline $\mathrm{C}_{22}$ & 5.02 & -31.4 & 0.6 \\
\hline $\mathrm{C}_{23}$ & 1.74 & -32.9 & 0.5 \\
\hline $\mathrm{C}_{24}$ & 6.41 & -31.7 & 0.5 \\
\hline $\mathrm{C}_{25}$ & 1.68 & -31.8 & 0.9 \\
\hline $\mathrm{C}_{26}$ & 8.01 & -32.1 & 0.5 \\
\hline $\mathrm{C}_{27}$ & 1.69 & -32.3 & 0.7 \\
\hline $\mathrm{C}_{28}$ & 8.68 & -31.7 & 0.9 \\
\hline $\mathrm{C}_{29}$ & 1.27 & -32.5 & 0.7 \\
\hline $\mathrm{C}_{30}$ & 4.48 & -33.2 & 0.7 \\
\hline $\mathrm{C}_{31}$ & 0.74 & -35.2 & 1.7 \\
\hline $\mathrm{C}_{32}$ & 2.24 & -34.0 & 0.9 \\
\hline Total & 67.99 & & \\
\hline CPI $\left(\mathrm{C}_{20}-\mathrm{C}_{32}\right)$ & 4.57 & & \\
\hline
\end{tabular}

$* n$ indicates the number of double bond of $C_{18}$ fatty acid.

We denote mono- and poly-unsaturated $C_{18}$ fatty acid as " $C_{18: n}$ ".

lary GC and GC/IRMS, respectively. The details of GC/ IRMS analyses are described elsewhere (Fang et al., 2002).

In order to isolate sufficient quantities of individual fatty acids for ${ }^{14} \mathrm{C}$ measurement by AMS, we used a PCGC system (HP 6890) equipped with cooled injector (CIS4, Gerstel, Germany), HP-5 fused silica megabore column (HP-5, $30 \mathrm{~m} \times 0.53 \mathrm{~mm}$ i.d., film thickness of $1.0 \mu \mathrm{m}$ ), zero-dead-volume effluent splitter, and cryogenic preparative fraction collector (PFC, Gerstel). More details of PCGC instrumentation are given elsewhere (e.g., Eglinton et al., 1996; Matsumoto et al., 2002). The injection volume was $25 \mu \mathrm{l}$ and the CIS is programmed from $25^{\circ} \mathrm{C}$ $(0.5 \mathrm{~min})$ to $350^{\circ} \mathrm{C}$ at $12^{\circ} \mathrm{C} \mathrm{sec}{ }^{-1}$ and held at $350^{\circ} \mathrm{C}$ for 6 min. The $\mathrm{GC}$ oven temperature was programmed from $50^{\circ} \mathrm{C}(1 \mathrm{~min})$ to $120^{\circ} \mathrm{C}$ at $30^{\circ} \mathrm{C} \mathrm{m^{-1 }}$, from $120^{\circ} \mathrm{C}$ to $310^{\circ} \mathrm{C}$ at $6^{\circ} \mathrm{C} \mathrm{min}^{-1}$ and then held at $310^{\circ} \mathrm{C}$ for $30 \mathrm{~min}$. Helium was used as the carrier gas. A total of 85 consecutive GC injections and subsequent PCGC runs were performed in order to isolate hundred microgram quanti- ties of individual saturated monocarboxylic acids. After the PCGC separation, fatty acid methyl esters were purified on a silica gel column to eliminate any methyl silicone contaminants that were derived from the stationary phase of $\mathrm{GC}$ column. We separated the $\mathrm{FA}$ fraction into individual $\mathrm{C}_{16}, \mathrm{C}_{18}, \mathrm{C}_{20}, \mathrm{C}_{22}, \mathrm{C}_{24}, \mathrm{C}_{26}, \mathrm{C}_{28}$ and $\mathrm{C}_{30}$ species.

The isolated fatty acid methyl esters were combusted in an evacuated quartz tube in the presence of $\mathrm{CuO}$ $\left(800^{\circ} \mathrm{C}, 2 \mathrm{hrs}\right)$ and the purified $\mathrm{CO}_{2}$ was then converted to a graphite target. Amounts of isolated fatty acid methyl esters ranged from $138 \mu \mathrm{g} \mathrm{C}$ to $271 \mu \mathrm{g} \mathrm{C}$. Graphitization of $\mathrm{CO}_{2}$ was conducted using a microscale technique developed for AMS ${ }^{14} \mathrm{C}$ analysis (Eglinton et al., 1996; Uchida et al., 2004). ${ }^{14} \mathrm{C}$ analyses of graphite targets were performed by the AMS facility (NIESTERRA) at the National Institute for Environmental Studies, Japan (Kume et al., 1997). To calculate $\Delta^{14} \mathrm{C}$ values of fatty acids, we corrected the value of esters using a simple mass balance equation amongst $\Delta^{14} \mathrm{C}$ values of 
Table 2. Carbon isotopic compositions of fatty acids isolated from bulk leaves of Taxus cuspidata $\left(C_{3}\right.$ plant $)$

\begin{tabular}{lccc}
\hline Carbon number & Relative abundance ${ }^{33}$ & $\delta^{13} \mathrm{C}(\%)$ & Standard deviation $(\%)$ \\
\hline $\mathrm{C}_{14}$ & 0.218 & -36.4 & 1.1 \\
$\mathrm{C}_{16}$ & 1 & -34.9 & 0.6 \\
$\mathrm{C}_{18}{ }^{* 1}$ & 4.48 & -35.9 & 1.7 \\
$\mathrm{C}_{20}$ & 0.104 & n.d.*4 & \\
$\mathrm{C}_{22}$ & 0.172 & -36.1 & 0.8 \\
$\mathrm{C}_{24}$ & 0.357 & -33.4 & 1.0 \\
$\mathrm{C}_{26}$ & 0.0988 & -32.4 & 0.9 \\
$\mathrm{C}_{28}$ & 0.0737 & -31.7 & 1.3 \\
$\mathrm{C}_{30} * 2$ & 0.0225 & -31.2 & \\
\hline
\end{tabular}

${ }^{* 1} C_{18}$ fatty acid includes $C_{18: 0}$ (saturated) and $C_{18: 1}$ (one double bond).

$*^{2} \delta^{13} C$ values of $C_{30}$ fatty acid was analyzed only one time because of low concentration.

${ }^{*}{ }^{3}$ The relative abundance when $C_{16} F A$ is 1.00 .

${ }^{*}{ }^{4}$ Not determined. $C_{20}$ fatty acid was omitted because of large standard deviation.

fatty acid, methyl group derived from a derivatizing reagent $\left(\mathrm{BF}_{3} /\right.$ methanol, $\left.\Delta^{14} \mathrm{C}=-998 \%\right)$ and methyl ester (Matsumoto et al., 2001). The data were corrected for isotopic fractionation using $\delta^{13} \mathrm{C}$ values (Stuiver and Polach, 1977).

\section{RESULTS AND DISCUSSION}

Molecular distribution of fatty acids and their stable carbon isotopic compositions

Homologous series of normal and branched fatty acids were detected in the soil sample as shown in Fig. 1. Their molecular distribution is characterized by the predominance of even carbon numbered fatty acids with two maxima at $\mathrm{C}_{16}$ and $\mathrm{C}_{28}$. The distribution pattern is similar to that of the plant leaves collected from the same sampling site (Zea mays, Fang et al., 2002; Taxus cuspidata, Matsumoto and Kawamura, unpublished data). This suggests that major source of FAs in the soil is litter from tree leaf and living plants nearby. Similar distribution has been reported in atmospheric aerosols (Matsumoto et al., 2001), riverine, estuarine and marine sediments (Naraoka et al., 1999).

However, there are two distinct differences in the molecular distributions between soil and plant leaf samples. First, iso- and anteiso- $\mathrm{C}_{15}$ and $\mathrm{C}_{17}$ species were found to be more abundant than corresponding normal species in the soil sample (see Fig. 1 and Table 1). Branched structures are not present in plant leaves, but abundant in bacteria (e.g., Kaneda, 1967, 1991). This suggests that plant-derived FAs, at least shorter chain $\mathrm{C}_{14}{ }^{-}$ $\mathrm{C}_{18}$, are modified by microbial activity. Second, the carbon preference index (CPI) for $\mathrm{C}_{20}-\mathrm{C}_{32}$ species in the soil sample was found to be 4.57 , which is defined by the concentration ratio of even carbon numbered fatty acids over odd carbon numbered acids. This value is much lower than that (19.1) found in the plant leaf sample collected at the sampling site (Taxus cuspidata: C3 plant, Matsumoto and Kawamura, unpublished data), but is close to that (5.45) of aerosol sample collected on the rooftop of ILTS (Matsumoto et al., 2004). Odd carbon numbered FAs can be produced by microbial $\alpha$-oxidation of even numbered homologues (Yano et al., 1971 and references therein), again suggesting a microbial modification of soil organic matter.

Table 1 gives stable carbon isotopic compositions of individual fatty acids in the soil sample. Their individual $\delta^{13} \mathrm{C}$ values, except for $\mathrm{C}_{14}-\mathrm{C}_{18}$ (-23.0 to $-28.1 \%$ ), ranged from -35.2 to $-30.2 \%$, which are $1.2-6.4 \%$ o lighter than the aerosol samples collected at the ILTS (Matsumoto et al., 2001, 2004). The stable carbon isotopic compositions of FAs in a bulk leaf sample, Taxus cuspidata, which grew near the sampling site ( $\mathrm{ca} .30 \mathrm{~m}$ away), ranged from -36.4 to $-31.2 \%$ (Table 2), suggesting that $\mathrm{C} 3$ plants are important contributors to fatty acids in soil (Chikaraishi et al., 2004). However, $\delta^{13} \mathrm{C}$ values of $\mathrm{C}_{16}$ and $\mathrm{C}_{18}$ species in soil are much heavier than those of the plant leaf sample by 6-10\%o (Tables 2 and 3). Further, heaviest values were found for branched and normal chain $\mathrm{C}_{15}$ and $\mathrm{C}_{17}$ species ( -23.0 to $-25.8 \%$ ), whose $\delta^{13} \mathrm{C}$ values are, at their maximum, $12 \%$ heavier than even numbered $\mathrm{C}_{14}$ $\mathrm{C}_{18}$ in the plant leaves growing at the sampling site (see Tables 1 and 2). The branched chain FAs are characteristic to sulfate-reducing (Boon et al., 1977; Parkes and Taylor, 1983) and gram-positive bacteria (Kaneda, 1967, 1991). These results suggest that major portions of $\mathrm{C}_{14}$ $\mathrm{C}_{18}$ species including branched $\mathrm{C}_{15}$ and $\mathrm{C}_{17}$ in soils were not directly derived from $\mathrm{C} 3$ plants, but were heavily modified by bacterial activity in soil. 
Microbial degradation and modification of fatty acids in soil

Living microorganisms in soil can account for a significant portion of the organic carbon mass and thus they should play an important role in the carbon cycle of a soil system. Microorganisms can utilize $\mathrm{C}_{16}-\mathrm{C}_{18}$ FAs more efficiently than longer chain FAs due to their water solubility and consequent permeability. Although carbon isotopic fractionation is not significant during bacterial degradation of $\mathrm{C}_{16}-\mathrm{C}_{18}$, an enrichment of ${ }^{13} \mathrm{C}$ in $\mathrm{C}_{16}-\mathrm{C}_{18}$ FAs can occur during a microbial re-synthesis of soil organic matter. Lichtfouse et al. (1995) conducted an incubation experiment of crop soils using unlabelled and labelled (ca. 500 per mil) glucose as a substrate and found that $n$ $\mathrm{C}_{14}-\mathrm{C}_{20}$ FAs became isotopically heavier by $2-15 \%$ during the incubation, while they reported no change in $\delta^{13} \mathrm{C}$ for longer chain FAs $>\mathrm{C}_{20}$. Together with the knowledge of Lichtfouse et al. (1995), our results suggest that microorganisms such as bacteria and fungi synthesize FAs in soils, whose $\delta^{13} \mathrm{C}$ values are heavier.

There are several additional sources that contribute to the heavier carbon isotopic ratios of $\mathrm{C}_{16}-\mathrm{C}_{18}$ FAs in a soil system, including animal activity. Small animals living in the soils could produce isotopically heavier FAs $\left(\mathrm{C}_{16}-\mathrm{C}_{18}\right)$ and contribute to the soil lipids. DeNiro and Epstein (1978) reported that the carbon isotopic composition of the whole body of an animal is about $0-1 \%$ o heavier than that of its diet on a basis of organic carbon level. According to Hammer et al. (1998), redhead ducks that had consumed a diet showed heavier carbon isotopic ratios of fatty acids by $3.7 \%$ than those of the diet. These results suggest that fatty acids in animals are enriched in ${ }^{13} \mathrm{C}$ during the digestion of the diet and re-synthesis/modification of shorter chain fatty acids possibly in guts where microbial activity is significant. Although large animals such as duck are not living in the sampling site, small animals should be abundant in a soil system of the sampling site and may contribute to the re-synthesis of fatty acids having heavier isotopic ratios.

As seen in Table $1, \delta^{13} \mathrm{C}$ values of longer chain FAs $>\mathrm{C}_{20}$ in the soil sample ranged from -35.2 to $-30.4 \%$. These values are similar to those obtained for $\mathrm{C} 3$ plant leaf (surface waxes, -32.3 to $-29.1 \%$, Fang et al., 2002; bulk tissues, -36.1 to $-31.2 \%$, Matsumoto and Kawamura, unpublished data). This is consistent with the idea that higher plant leaves are the major source of longer chain FAs in soils. It is of interest to note that $\delta^{13} \mathrm{C}$ values of longer-chain FAs are also similar to those of aerosol samples ( -30.8 to $-27.8 \%$, Matsumoto et al., 2004), and river sediment samples in Japan (-36.5 to $-31.2 \%$, Naraoka et al., 1999). These results demonstrate that the longer chain FAs $>\mathrm{C}_{20}$ in soils are not seriously metabolized by microorganisms and thus their isotopic compositions are rather preserved during the biogeochemical processes in soils due to their hydrophilic properties. This is in contrast to the case of shorter chain fatty acids.

A stability of longer chain FAs in a soil system is further supported by the similarity of $\delta^{13} \mathrm{C}$ values $(-35.2$ to $-30.5 \%$ ) of odd carbon numbered fatty acids $\left(>\mathrm{C}_{20}\right)$ that are scarcely present in higher plants to those of even carbon numbered FAs $>\mathrm{C}_{20}(-34.5$ to $-30.4 \%$, see Table 1$)$. As described above, the CPI (4.57) of fatty acids in the soil is much lower than that expected from the adjacent tree leaves $(\mathrm{CPI}=19.1)$, suggesting an enzymatic $\alpha$-oxidation in a soil system. If odd carbon numbered long chain FAs were newly synthesized in soils by bacteria, their $\delta^{13} \mathrm{C}$ values would be similar to those of $i$ SO- $^{-}$, anteisoand normal- $\mathrm{C}_{15}$ and $\mathrm{C}_{17}$ species ( -25.8 to $-23.0 \%$, see Table 1). However, $\delta^{13} \mathrm{C}$ values of odd numbered $\mathrm{C}_{21}-$ $\mathrm{C}_{31}$ FAs did not show the similarity, but are equivalent to those of even $\mathrm{C}_{20}-\mathrm{C}_{32}$ FAs. This suggests that oddcarbon numbered longer chain FAs can be produced by soil microbes via enzymatic $\alpha$-oxidation of even carbon numbered FAs of tree leaf origin (Yano et al., 1971), however, the isotopic fractionation is negligible.

Preferential degradation of shorter chain FAs and bacterial re-synthesis of fatty acids including iso/anteiso branched chain species have been reported in the lake sediments from various locations (e.g., Matsuda and Koyama, 1977; Kawamura and Ishiwatari, 1984), although their stable carbon isotopic compositions were not studied. A similar biogeochemical process should occur in the soil system. Preferential microbial degradation of shorter chain FAs may be related to their watersolubility. Shorter chain species are more water-soluble and thus can be mobilized in soils and taken by bacteria to be digested. In contrast, longer chain FAs are less water-soluble and are not efficiently mobilized, as discussed above. Thus they are more refractory to microbial degradation and stay longer in the soil system (Moucawi et al., 1981). Similarly, shorter chain FAs in litters can be dissolved in rainwater and downward transported in the subsurface soil whereas longer chain FAs cannot be dissolved in the water and are less mobilized. Hence longer chain FAs are more likely retained in the same soil layer with smaller turnover rates.

Radiocarbon content in individual fatty acids and biogeochemical processes in subsurface soil

Table 3 presents $\Delta^{14} \mathrm{C}$ values of individual FAs in the soil sample. Unfortunately, data is not available for $\mathrm{C}_{16}$ species due to loss of the fraction during the formation and purification steps of microscale graphite target. Here we report, for the first time, a significant diversity of $\Delta^{14} \mathrm{C}$ values of various fatty acids in a soil sample ranging from +16.7 to $+127.6 \%$. We found that the ${ }^{14} \mathrm{C}$ values of fatty acids are largely dependent on their carbon numbers: shorter chain FAs (unsaturated $\mathrm{C}_{18: n}$ and saturated $\mathrm{C}_{18: 0}$ ) 
Table 3. The ${ }^{14} \mathrm{C}$ data for individual fatty acids in the soil sample

\begin{tabular}{lcccc}
\hline Carbon number & Purity $(\%)^{* 1}$ & yield $(\mu \mathrm{g})^{* 2}$ & $\Delta^{14} \mathrm{C}(\% \circ)$ & Standard deviation $(\%)^{* 3}$ \\
\hline $\mathrm{C}_{18}$ & 100 & 105 & 127.6 & 1.5 \\
$\mathrm{C}_{18 n}$ & 100 & 224 & 96.3 & 1.9 \\
$\mathrm{C}_{20}$ & 100 & 149 & 74.3 & 1.4 \\
$\mathrm{C}_{22}$ & 99 & 177 & 74.9 & 1.4 \\
$\mathrm{C}_{24}$ & 100 & 227 & 98.7 & 1.4 \\
$\mathrm{C}_{26}$ & 96 & 249 & 79.1 & 0.9 \\
$\mathrm{C}_{28}$ & 97 & 271 & 19.8 & 1.3 \\
$\mathrm{C}_{30}$ & 95 & 136 & 16.7 & 1.1 \\
\hline
\end{tabular}

\footnotetext{
*I Purity of each compound was compared with their various peaks on the PCGC chromatograms, which were defined as impure compounds.

$*^{2}$ Yield was calculated from the isolated PCGC peak.

${ }^{*}$ Standard deviation was calculated from duplicate analyses.
}

showed higher values $(96.3$ to $127.6 \%$ ) whereas longer chain FAs $\left(\mathrm{C}_{28}\right.$ and $\left.\mathrm{C}_{30}\right)$ gave lower values (16.7 to $19.8 \%$ ). The values of $C_{20}-C_{26}$ species (74.3-98.7\%o) are in between two groups. Positive $\Delta{ }^{14} \mathrm{C}$ values of shorter chain FAs do not correspond to any $\Delta^{14} \mathrm{C}$ values of atmospheric carbon dioxide before the nuclear bomb tests that started in 1960 (Levin et al., 1985; Levin and Kromer, 1997; Hua and Berbetti, 2004), but correspond to the values for the atmospheric carbon dioxide after 1993 or in 1957-1958 (Hua and Berbetti, 2004). On the other hand, $\Delta^{14} \mathrm{C}$ values of $\mathrm{C}_{28}$ and $\mathrm{C}_{30}$ FAs are close to the carbon values of pre-bomb age in 1955 (Hua and Berbetti, 2004).

The higher $\Delta{ }^{14} \mathrm{C}$ values found in the shorter FAs raised an important question; why are shorter FAs enriched with younger carbons in subsurface soil? As discussed in Subsection "Microbial degradation and modification of fatty acids in soil", selective degradation of shorter FAs is an important process in a soil system. This process can explain the ${ }^{14} \mathrm{C}$ enrichment of shorter FAs over longer FAs in the subsurface soil if FAs are supplied into the soil system from living plants. In a closed system of soil layers, there should be no difference in $\Delta^{14} \mathrm{C}$ values among the remaining FAs even after serious microbial selective degradation of shorter chain FAs and radiocarbon decay. However, in a real soil layer where the system is open to the ground surface, modern carbon can be supplied to the subsurface soil by several pathways as discussed later, causing heavier $\Delta^{14} \mathrm{C}$ values of shorter FAs relative to longer FAs. Selective degradation of shorter chain FAs coupled with a continuous supply of fresh organic matter to the subsurface soil should be a primary factor to control the diversity of radiocarbon contents of fatty acids in soil system (Fig. 2). Alternatively, shorter FAs in soil can be preferentially dissolved in precipitation waters and subsequently removed.

The ${ }^{14} \mathrm{C}$ enrichment in the shorter chain FAs can be caused by preferential transport of fresh organic carbon to the subsurface soil. Because shorter chain FAs are more water-soluble than longer chain FAs, the former can be mobilized in the litters and be transported downward by precipitation waters to be utilized by soil bacteria. They could also be mobilized in the tree stem/root system and transported downward to the roots and released to the subsurface soil layer. In contrast, longer chain FAs that are enriched in leaf wax are less water-soluble and thus are not likely transported via a stem down to the roots in soils. Here we propose biogeochemical pathways as the source of shorter FAs that can further enhance the diversity of the $\Delta^{14} \mathrm{C}$ values of individual FAs in soil: (1) downward transport of fresh carbon to subsurface soil via infusion of shorter chain FAs and other water-soluble organics from litters by meteoric waters and subsequent microbial re-synthesis of shorter FAs, (2) stem transport of shorter chain FAs and other water-soluble organics from tree leaves down to fine roots followed by the subsequent release to subsurface soils and microbial re-synthesis.

First, leaf litters that contain various organic compounds including fatty acids, carbohydrates and amino acids are an important source of soil organic matter. The litters are subjected to animal grazing and microbial degradation on the soil surfaces. The water-soluble organic compounds in the litters and their degradation products can be dissolved in wet precipitation and transported downward to the subsurface soil, where bacteria can utilize them as an energy source and re-synthesize lipids including short chain FAs. As shown in Fig. 2 (see pathway 1), infusion of water-soluble organics from litters and the subsequent downward transport by rainwaters are an important process to relocate modern carbon from plant leaves into the subsurface soil. This pathway is consistent with the organic geochemical evidence obtained from molecular composition and stable carbon isotopic ratios of soil fatty acids as discussed above, and can also explain the apparent enrichment of radiocarbon in shorter 


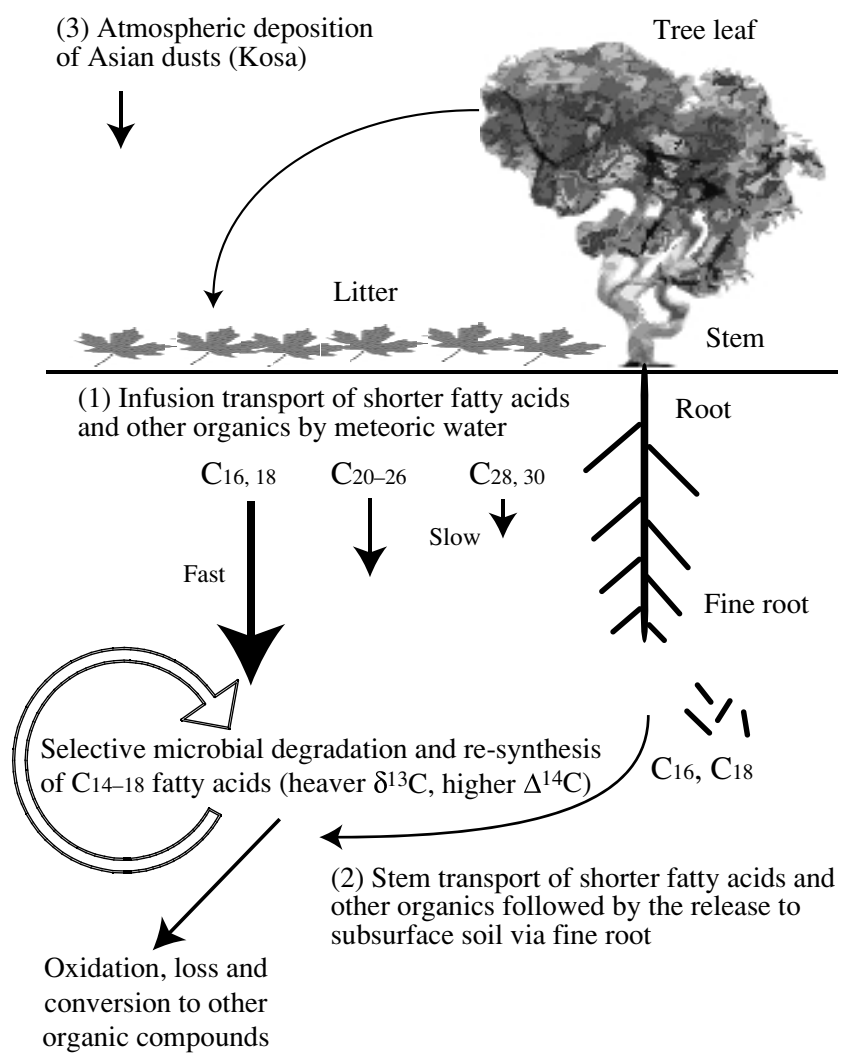

Fig. 2. Proposed biogeochemical pathways for selective microbial degradation of plant-derived fatty acids and re-synthesis of shorter chain acids in the subsurface soil. Combination of selective microbial degradation and inputs of fresh carbon to the soil are responsible to the higher $\Delta^{14} C$ values. For more details, see Subsection "Radiocarbon content in individual fatty acids and biogeochemical processes in subsurface soil”.

chain FAs.

Second, roots may act as an important pathway to transport photosynthesized modern carbon in the plant leaf down to the subsurface soil. Maudinas et al. (1982) reported distributions of FAs in roots of Alnus species in both laboratory and field studies, where short chain $\mathrm{C}_{16}$ and $\mathrm{C}_{18}$ are dominant. Moreover, Gaudinski et al. (2001) reported $\Delta{ }^{14} \mathrm{C}$ values of +116 to $+377 \%$ or for bulk carbon in the fine roots of the same species taken from the subsurface soil (45 cm in depth). Although the reported $\Delta^{14} \mathrm{C}$ values are higher than those obtained for short chain fatty acids in our soil sample, they are more typical to modern carbon that is influenced by atomic bomb tests. This suggests that stem transport of modern carbon from plant leaves to the roots can explain the high $\Delta^{14} \mathrm{C}$ values of fatty acids in our soil (see pathway 2, Fig. 2), except for $\mathrm{C}_{28}$ and $\mathrm{C}_{30}$ species (see Table 3 ).

Although it is not possible to distinguish whether shorter FAs in fine roots are transported from leaves via stem or they are in situ synthesized, fine roots may not be the direct source of shorter chain FAs in our soil sample because their molecular and $\delta^{13} \mathrm{C}$ composition suggested extensive bacterial alteration. Fine roots should also release other organic molecules such as carbohydrates and amino acids, which can be utilized by microbes to synthesize short chain FAs such as $n-\mathrm{C}_{16}$ and $n-\mathrm{C}_{18}$ as well as branched (iso-/anteiso-) and normal chain $\mathrm{C}_{15}$ and $\mathrm{C}_{17}$, which are all detected in our soil sample (see Table $1)$. This process also contributes to heavier $\delta^{13} \mathrm{C}$ values of $\mathrm{C}_{14}$ to $\mathrm{C}_{18}$ acids than longer chain acids $\left(>\mathrm{C}_{20}\right)$ (Table 1) via microbial processes as discussed above (DeNiro and Epstein, 1978; Hammer et al., 1998). However, their $\Delta^{14} \mathrm{C}$ values should be preserved during microbial activity. Hence pathway 2 (Fig. 2) should also be responsible to the downward transport of young carbon to the subsurface soil.

In contrast, longer chain acids are water-insoluble and less mobilized to be transported downward in the soil. Interestingly, the longest $\mathrm{C}_{28}$ and $\mathrm{C}_{30}$ FAs showed $\Delta^{14} \mathrm{C}$ values close to those of pre-atomic bomb age, indicating that the infusion transport and/or stem transport of longer chain species to subsurface soil is unlikely due to their hydrophobic properties. Meanwhile $\mathrm{C}_{20}-\mathrm{C}_{26}$ FAs showed $\Delta^{14} \mathrm{C}$ values of $74-99 \%$, which are close to those of shorter chain FAs. Since $\mathrm{C}_{20}-\mathrm{C}_{26}$ FAs are rarely present in roots (Maudinas et al., 1982) and are slightly hydrophilic, the moderate $\Delta^{14} \mathrm{C}$ values of $\mathrm{C}_{20}-\mathrm{C}_{26}$ FAs may be associated with the downward transport from the decaying leaves to the subsurface soil by precipitation.

Matsumoto et al. (2001) carried out radiocarbon analysis of individual FAs separated from aerosol particles collected in Sapporo (the same area) and reported that $\mathrm{C}_{24}$ plus $\mathrm{C}_{26}$ species showed ${ }^{14} \mathrm{C}$ ages of $5860( \pm 200)$ years old BP. These aged fatty acids could be long-range transported from the Asian continent. Based on the average flux of Asian dusts over the Japanese Islands (1-2 g $\mathrm{m}^{-2} \mathrm{yr}^{-1}$ ) (Kanamori et al., 1991) and the concentrations of FAs (200 ppm) in the Chinese yellow dusts that were collected in Sapporo as dry deposition (Kariya, 2007), atmospheric fluxes of long-range transported FAs over Japan are calculated to be $2-4 \mathrm{mg} \mathrm{m}^{-2} \mathrm{yr}^{-1}$. Interestingly, these air-to-soil fluxes are equivalent to those $(2.45 \mathrm{mg}$ $\mathrm{m}^{-2} \mathrm{yr}^{-1}$ ) estimated for the annual flux of FAs from canopy litters $\left(245 \mathrm{~g} \mathrm{~m}^{-2} \mathrm{yr}^{-1}\right)$ at the Calhorn Experimental Forest, South Carolina, USA (Richter et al., 1999), assuming fatty acid concentration of $10 \mathrm{ppm}$ in litter fall. Because longer chain FAs are important constituents of Chinese loess samples (Matsumoto and Kawamura, unpublished results), the dusts may contribute to lowering the $\Delta{ }^{14} \mathrm{C}$ values of longer chain FAs in the soil. Due to their slow turnover rates relative to shorter FAs in soils, atmospheric dust deposition of longer FAs may also be important in the biogeochemical cycle of carbon in soil. 
Although there has been no reported data on $\Delta^{14} \mathrm{C}$ values of shorter and longer chain FAs in soils, there are a few studies on the $\Delta^{14} \mathrm{C}$ measurement of various FAs in marine sediments (Uchida et al., 2000, 2001). Uchida et al. (2001) reported higher $\Delta^{14} \mathrm{C}$ values for shorter chain $\left(\mathrm{C}_{14}-\mathrm{C}_{18}\right)$ fatty acids than longer $\left(\mathrm{C}_{26}-\mathrm{C}_{28}\right)$ fatty acids in the subsurface $(11-15 \mathrm{~cm}$ in depth) sediments from the western North Pacific. Their results are very similar to our subsurface soil sample, although no mechanisms have been proposed for the diversity of $\Delta^{14} \mathrm{C}$ of various fatty acids. Those results could also be interpreted by preferential degradation of shorter FAs, coupled with the downward supply of fresh carbon from the upper sedimentary layer probably due to bioturbation. Atmospheric deposition of aged Asian soil dusts may also act as an important cause to increase the $\Delta^{14} \mathrm{C}$ values of shorter chain FAs in marine sediments.

\section{SUMMARY AND CONCLUSIONS}

Comparison of molecular composition (e.g., chain length, normal/branched, odd/even carbon numbers) between soil and plant leaf samples demonstrated that longer chain acids $>\mathrm{C}_{20}$ in soil are primarily derived from higher plant leaves whereas shorter chain acids $<\mathrm{C}_{20}$ are significantly modified by microbial activities in soils. We found heavier $\delta^{13} \mathrm{C}$ ratios $(-23.0$ to $-28.1 \%$ ) of normal and branched shorter chain acids $\left(\mathrm{C}_{14}-\mathrm{C}_{18}\right)$ than longer chain acids ( -35.2 to $-30.2 \%$ ), supporting extensive microbial decomposition of organic matter and re-synthesis of fatty acids in a soil system. We also found higher $\Delta^{14} \mathrm{C}$ values of shorter chain acids $(+96$ to $+127 \%$ ) than longer chain acids $(+16$ to $+98 \%)$ in the subsurface soil. The higher values can be explained by a combination of the decay of ${ }^{14} \mathrm{C}$ and selective degradation of shorter chain acids under a continuous input of fresh carbon to subsurface soil. Photosynthesized fresh carbons can be downward transported to subsurface soil by infusion of water-soluble organic matter from litters with meteoric waters and/or by a tree stem and root transport followed by a release to soil. Soil bacteria should utilize the modern carbon to synthesize shorter chain fatty acids having higher $\Delta^{14} \mathrm{C}$ values.

Selective microbial degradation of shorter chain fatty acids and the downward transport in the soil system are due to their physicochemical properties; shorter chain acids are more hydrophilic and thus more mobilized in soil whereas longer acids are less hydrophilic and thus less mobilized. These differences also affect the microbial turnover rates of fatty acids in soils. This study also suggests that soil microbial activity contributes significantly to mineralize photosynthesized organic carbon to $\mathrm{CO}_{2}$ (Fig. 2). In contrast, longer chain fatty acids of plant leaf wax origin can stay longer in soil without serious degradation due to their hydrophobic properties. They may contribute to the accumulation of refractory organic matter in soils. Although the stable and radiocarbon analyses of fatty acids provide useful tools to understand biogeochemical processes, further studies are needed including vertical profiles of molecular and stable/radiocarbon compositions of fatty acids in a soil system.

Acknowledgments - This work was in part supported by the Japanese Ministry of Education, Science, Sports, and Culture through Grant-in-Aid 10354009, as well as by the Budget for Nuclear Research of the Ministry of Education, Culture, Sports, Science and Technology, based on the screening and counseling by the Atomic Energy Commission. Part of this study also was financially supported by MIO, JAMSTEC. We gratefully appreciated T. Kobayashi and C. Kobayashi, for operating the AMS in NIES-TERRA. We also thank T. Akagi, T. Nakatsuka and M. Minami for their critical reading and constructive comments. We also thank for the financial support from Japan Society for the Promotion of Science to K.M.

\section{REFERENCES}

Amblès, A., Parlanti, E., Jambu, P., Mayoungou, P. and Jacquesy, J.-C. (1994) n-Alkane oxidation in soil. Formation of internal monoalkenes. Geoderma 64, 111-124.

Becker-Heidmann, P., Andresen, O., Kalmar, D., Scharpenseel, H.-W. and Yaalon, D. H. (2002) Carbon dynamics in vertisols as revealed by high-resolution sampling. Radiocarbon 44, 63-73.

Boon, J. J., de Leeuw, J. W., Hoek, G. J. and Vosjan, J. H. (1977) Significance and taxonomic value of iso and anteiso monoenoic fatty acids and branched $\beta$-hydroxy acids in Desulfovibrio desulfuricans. J. Bacteriol. 129, 631-644.

Chikaraishi, Y., Naraoka, H. and Poulson, S. R. (2004) Hydrogen and carbon isotopic fractionations of lipid biosynthesis among terrestrial (C3, C4 and CAM) and aquatic plants. Phytochemistry 65, 1369-1381.

DeNiro, M. J. and Epstein, S. (1978) Influence of diet on the distribution of carbon isotopes in animals. Geochim. Cosmochim. Acta 42, 495-506.

Eglinton, T. I., Aluwihare, L. I., Bauer, J. E., Druffel, Z. R. M. and McNichol, A. P. (1996) Gas chromatographic isolation of individual compounds from complex matrices for radiocarbon dating. Anal. Chem. 68, 904-912.

Fang, J., Kawamura, K., Ishimura, Y. and Matsumoto, K. (2002) Carbon isotopic composition of fatty acids in the marine aerosols from the western north pacific: Implication for the source and atmospheric transport. Environ. Sci. Technol.36, 2598-2604.

Food and Agriculture Organization of the United Nations (1998) World Reference Base for Soil Resources. Rome.

Gagosian, R. B. and Peltzer, E. T. (1986) The importance of atmospheric input of terrestrial organic material to deep sea sediments. Org. Geochem. 10, 661-669.

Gaudinski, J. B., Trumbore, S. E., Davidson, E. A. and Zheng, S. (2000) Soil carbon cycling in a temperate forest: Radiocarbon-based estimates of residence times, sequestration 
rates and partitioning of fluxes. Biogeochem. 51, 33-69.

Gaudinski, J. B., Trumbore, S. E., Davidson, E. A., Cook, A. C., Markewitz, D. and Richter, D. D. (2001) The age of fine-root carbon in three forests of the eastern United States measured by radiocarbon. Oecologia 129, 420-429, doi:10.1007/s004420100746.

Genty, D., Vokal, B., Obelicc, B. and Massault, M. (1998) Bomb ${ }^{14} \mathrm{C}$ time history recorded in two modern stalagmitesimportance for soil organic matter dynamics and bomb ${ }^{14} \mathrm{C}$ distribution over continents. Earth Planet. Sci. Lett. 160, 795-809.

Hammer, B. T., Fogel, M. L. and Hoering, T. C. (1998) Stable carbon isotope ratios of fatty acids in seagrass and redhead ducks. Chem. Geol. 152, 29-41.

Hayes, J. M., Freeman, K. H., Popp, B. N. and Hoham, C. H. (1990) Compound-specific isotopic analyses: A novel tool for reconstruction of ancient biogeochemical processes. Org. Geochem. 16, 1115-1128.

Hua, Q. and Barbetti, M. (2004) Review of tropospheric bomb ${ }^{14} \mathrm{C}$ data for carbon cycle modeling and age calibration purposes. Radiocarbon 46, 1273-1298.

Huang, Y., Lockheart, M. J., Logan, G. A. and Eglinton, G. (1996) Isotope and molecular evidence for the diverse origins of carboxylic acids in leaf fossils and sediments from the Miocene Lake Clarkia deposit, Idaho, U.S.A. Org. Geochem. 24, 289-299.

Huebert, B. J., Bates, T., Russell, P. B., Shi, G., Kim, Y. J., Kawamura, K., Carmichael, G. and Nakajima, T. (2003) An overview of ACE-Asia: Strategies for quantifying the relationships between Asian aerosols and their climatic impacts. J. Geophys. Res. 108(D23), 8633, doi:10.1029/ 2003JD003550.

Intergovernmental Panel for Climate Change (IPCC) 2001 (2001) Climate Change 2001: The Scientific Basis (Houghton, J. T. et al., eds.), Cambridge Univ. Press, 859 pp.

Kanamori, S., Kanamori, N., Nishikawa, M. and Mizoguchi, T. (1991) Chemistry of Kosa. Kosa (Institute for Hydrospheric Atmospheric Science, Nagoya University, ed.), 124-156, Kokin Shoin Press, Tokyo.

Kaneda, T. (1967) Fatty acids in the genus Bacillus, I. Iso- and anteiso-fatty acids as characteristic constituents of lipids in 10 species. J. Bacteriol. 93, 894-903.

Kaneda, T. (1991) Iso- and anteiso-fatty acids in bacteria: Biosynthesis, function, and taxonomic significance. Microbiol. Rev. 55, 288-302.

Kariya, T. (2007) Molecular composition and seasonal variation of lipid class compounds in the atmospheric aerosols collected at Gosan site in Jeju Island. Masters Thesis, Graduate School of Environmental Science, Hokkaido University.

Kawamura, K. (1995) Land-derived lipid class compounds in the deep-sea sediments and marine aerosols from North Pacific. Biogeochemical Processes and Ocean Flux in the Western Pacific (Sakai, H. and Nozaki, Y., eds.), 31-51, Terra Scientific Publishing Co., Tokyo.

Kawamura, K. and Ishiwatari, R. (1984) Fatty acid geochemistry of a 200-meter sediment core from Lake Biwa, Japan. Early diagenesis and paleoenvironmental information. Geochim. Cosmochim. Acta 48, 251-266.
Kawamura, K., Kobayashi, M., Tsubonuma, N., Mochida, M., Watanabe, T. and Lee, M. (2004) Organic and inorganic compositions of marine aerosols from East Asia: Seasonal variations of water-soluble dicarboxylic acids, major ions, total carbon and nitrogen, and stable $\mathrm{C}$ and $\mathrm{N}$ isotopic composition. Geochemical Investigation in Earth and Space Science: A Tribute to Issac R. Kaplan (Hill, R. J. et al., eds.), 243-265, The Geochemical Society, Publications Series No. 9, Elsevier Science Ltd.

Kramer, C. and Gleixner, G. (2006) Variable use of plant- and soil-derived carbon by microorganisms in agricultural soils. Soil Biol. Biochem. 38, 3267-3278.

Kume, H., Shibata, Y., Tanaka, T., Yoneda, M., Kumamoto, Y. and Morita, M. (1997) The AMS facility at the National Institute for Environmental Studies (NIES), Japan. Nucl. Instr. and Meth. B 123, 31-33.

Levin, I. and Kromer, B. (1997) Twenty years of atmospheric ${ }^{14} \mathrm{CO}_{2}$ observations at Schauinsland Station, Germany. $R a$ diocarbon 39, 205-218.

Levin, I., Kromer, B., Schoch-Fisher, H., Bruns, M., Munnich, M., Berdau, D., Vogel, J. C. and Munnich, K. O. (1985) 25 years of tropospheric ${ }^{14} \mathrm{C}$ observations in Central Europe. Radiocarbon 27, 1-19.

Lichtfouse, É. (2000) Compound-specific isotope analysis. Application to archaeology, biomedical sciences, biosynthesis, environment, extraterrestrial chemistry, food science, forensic science, humic substances, microbiology, organic geochemistry, soil science and sport. Rapid Commun. Mass Spectrom. 14, 1337-1344.

Lichtfouse, É., Berthier, G., Houot, S., Barriuso, E., Bergheaud, V. and Vallaeys, T. (1995) Stable carbon isotope evidence for the microbial origin of $\mathrm{C}_{14}-\mathrm{C}_{18} n$-alkanoic acids in soils. Org. Geochem. 23, 849-852.

Lichtfouse, É., Bardoux, G., Mariotti, A., Balesdent, J., Ballentine, D. C. and Macko, S. A. (1997a) Molecular, ${ }^{13}$ C, and ${ }^{14} \mathrm{C}$ evidence for the allochthonous and ancient origin of $\mathrm{C}_{16}-\mathrm{C}_{18}$ n-alkanes in modern soils. Geochim. Cosmochim. Acta 61, 1891-1898.

Lichtfouse, É., Budzinski, H., Garrigues, P. and Eglinton, T. I. (1997b) Ancient polycyclic aromatic hydrocarbons in modern soils: ${ }^{13} \mathrm{C},{ }^{14} \mathrm{C}$ and biomarker evidence. Org. Geochem. 26, 353-359.

Matsuda, H. and Koyama, T. (1977) Early diagenesis of fatty acids in lacustrine sediments-I. Identification and distribution of fatty acids in recent sediment form a fresh water lake. Geochim. Cosmochim. Acta 41, 777-783.

Matsumoto, K., Kawamura, K., Uchida, M., Shibata, Y. and Yoneda,, M. (2001) Compound specific radiocarbon and $\delta^{13} \mathrm{C}$ measurements of fatty acids in a continental aerosol sample. Geophys. Res. Lett. 28, 4587-4590.

Matsumoto, K., Kawamura, K., Uchida, M. and Shibata, Y. (2002) Compound specific radiocarbon analysis and its application to various geochemical and environmental samples. Chikyukagaku (Geochemistry) 36, 149-159.

Matsumoto, K., Uchida, M., Kawamura, K., Shibata, Y. and Morita, M. (2004) Radiocarbon variability of fatty acids in semi-urban aerosol samples. Nucl. Instr. and Meth. B 223224, 842-847.

Maudinas, B., Chemardin, M. and Gadal, P. (1982) Fatty acid 
composition of roots and root nodules of Alnus species. Phytochem. 21, 1271-1273.

Moucawi, J., Fustec, E., Jambu, P. and Jacquesy, R. (1981) Decomposition of lipids in soils: Free and esterified fatty acids, alcohols and ketones. Soil Biol. Biochem. 13, 461468.

Naraoka, H., Yamada, K. and Ishiwatari, R. (1999) Carbon isotopic compositions of individual long-chain $n$-fatty acids and $n$-alkanes in sediments from river to open ocean: Multiple origins for their occurrence. Geochem. J. 33, 215-235.

Neff, J. C., Townsend, A. R., Gleixnerk, G., Lehman, S. J., Turnbull, J. and Bowman, W. D. (2002) Variable effects of nitrogen additions on the stability and turnover of soil carbon. Nature 419, 915-917.

Parkes, R. J. and Taylor, J. (1983) The relationship between fatty acid distributions and bacterial respiratory types in contemporary marine sediments. Estuar. Coastal Shelf Sci. 16, 173-189.

Pearson, A., MeNichol, A. P., Benitez-Nielson, B. C., Hayes, J. M. and Eglinton, T. I. (2001) Origins of lipid biomarkers in Santa Monica Basin surface sediment: A case study using compound-specific analyses. Geochim. Cosmochim. Acta 65, 3123-3137.

Perry, K., Cahill, D., Thomas, A., Schnell, R. C. and Harris, J. M. (1999) Long-range transport of anthropogenic aerosols to the National Oceanic and Atmospheric Administration baseline station at Mauna Loa Observatory, Hawaii. $J$. Geophys. Res. 104(D15), 18521-18533.

Richter, D. D., Markewitz, D., Trumbore, S. E. and Wells, C. G. (1999) Rapid accumulation and turnover of soil carbon in a re-establishing forest. Nature 400, 56-58.

Smittenberg, R. H., Eglinton, T. I., Schouten, S., Sinninghe
Damsté, J. S. (2006) Ongoing buildup of refractory organic carbon in boreal soils during the Holocene. Science 314, 1283-1286.

Stuiver, M. and Polach, H. A. (1977) Discussion: reporting of ${ }^{14} \mathrm{C}$ data. Radiocarbon 19, 355-363.

Tissot, B. P. and Welte, D. H. (1984) Petroleum Formation and Occurrence. Springer Verlag, Berlin, 699 pp.

Uchida, M., Shibata, Y., Kawamura, K., Yoneda, M., Mukai, H., Tanaka, A., Uehiro, T. and Morita, M. (2000) Isolation of individual fatty acids in sediments using preparative capillary gas chromatography (PCGC) for radiocarbon analysis at NIES-TERRA. Nucl. Instr. and Meth. B 172, 583588.

Uchida, M., Shibata, Y., Kawamura, K., Kumamoto, Y., Yoneda, M., Ohkushi, K., Harada, N., Hirota, M., Mukai, H., Tanaka, A., Kusakabe, M. and Morita, M. (2001) Compoundspecific radiocarbon ages of fatty acids from marine sediments from the western North Pacific. Radiocarbon 43, 2B, 949-956.

Uchida, M., Shibata, Y., Yoneda, M., Kobayashi, T. and Morita, M. (2004) Technical progress in AMS microscale radiocarbon analysis. Nucl. Instr. and Meth. B 223-224, 313-317.

United States Department of Agriculture (2003) Keys to Soil Taxonomy Ninth Edition. Data are also available at http:// soils.usda.gov/technical/classification/tax_keys/

Yano, I., Furukawa, Y. and Kusunose, M. (1971) $\alpha$-Oxidation of long-chain fatty acids in cell-free extracts of Arthrobacter simplex. Biochim. Biophys. Acta 239, 513-516.

Zhou, G., Liu, S., Li, Z., Zhang, D., Tang, X., Zhou, C., Yan, J. and Mo, J. (2006) Old-growth forests can accumulate carbon in soils. Science 314, 1417, doi:10.1126/science. 1130168 . 